\title{
Viewpoint
}

\section{A stitch in time: case for assessing the burden of delayed surgery}

\author{
C David Naylor, Pamela M Slaughter
}

Waiting lists for surgery are now found in most national health systems. As epiphenomena of a mismatch between supply and demand, surgical queues raise important issues of equity and efficiency. Equitable management of queues necessitates giving priority to those in greatest need, whereas efficiency hinges on ensuring the largest possible improvements in health outcomes for any level of resource inputs that shortens queues. Concepts of measurable needs or health outcomes, in turn, require an approach to queues that goes beyond simply counting heads in the queue or calculating waiting times. What matters, above all, is how new or existing resources can be used to minimise the measurable burden of delay. Our viewpoint here follows as a matter of course: both the burdens of delayed treatment and the impact of manoeuvres to mitigate that burden must be more systematically assessed with rigorous research methods.

World-weary consultants and managers may perceive that measuring the negative impact of queues is tantamount to a blinding view of the glaringly obvious. Moreover, the waiting list issue has been politicised in every jurisdiction where patients wait long times for specialised services. Perhaps the political uses of queues explain why published reports on waiting lists are occasionally blasé or fatalistic in tone, featuring reports on surgical non-attenders and the exaggerated numbers of patients in a given list, or tallies of how many patients in the queue did not really need surgery. Sociological analysis underscores the skein of behavioural and organisational complexities associated with waiting lists. ${ }^{1}$ If, however, as Osler argued, the purpose of medicine is to increase the net amount of happiness in the world, the vital issue is surely the burden borne by patients who need surgery and must wait for it.

\section{Positive effects of queueing}

Notwithstanding the rhetoric from the United States, some clinicians and most administrators acknowledge that queueing in a universal health care system has positive effects. Patients, in theory, can be ranked according to two principles that maintain equity: first come, first served and worst off, first on. This is arguably preferable to the American style maldistribution of services by income and insurance cover. Moreover, a system without waiting lists must have excessive capacity or it cannot give rapid treatment to urgent and non-urgent cases alike.

Queues may promote healing by tincture of time, since patients with less severe conditions tend to be put off the longest. For example, one study from Oxford's Radcliffe Infirmary found that $20 \%$ of children and $8 \%$ of adults on the waiting list for tonsillectomy improved sufficiently to decide against surgery. ${ }^{2}$ While outcomes researchers urge acceptance of "watchful waiting" as an alternative to early surgery for prostatism in the United States, ${ }^{3}$ surgical queueing in other parts of the world may work to the same end. Surgeons, too, have a chance for second thoughts. A clinic to manage a lengthening waiting list for varicose vein surgery at Bristol Royal Infirmary determined that 85 of 304 patients did not require surgery. ${ }^{4}$ Similarly, when 103 patients who had waited more than two years for orthopaedic surgery were seen at an Auckland review clinic 23 were removed from the list as having "insufficient pain or disability." But here, as noted earlier, the picture may be badly framed. Should our concern be the $22 \%$ who did not need surgery, or the $78 \%$ who waited two years with remediable pain and disability?

\section{Measuring the burden of delay: why and how}

We believe that there is nothing equitable or efficient in lengthy queues for hip replacement that see patients with disabling arthritis become housebound or in avoidable deaths among people waiting for coronary artery bypass grafting. Furthermore, major variations in the length of queues among regions, hospitals, and surgical services have been well documented in Britain $^{6}$ and elsewhere. ${ }^{78}$ These disparities threaten the validity of arguments that queueing is an equitable method of managing access to finite resources. Equity and efficiency are also ill served when poor prioritisation leads to a mismatch between clinical severity and waiting time, as has been reported for individual hospitals or surgeons. ${ }^{9-11}$

Indeed, the lack of consistent list management has led analysts to question the term "surgical queue" as implying a degree of orderliness and turnover that may not be 
present; analogies are instead drawn to a mortlake or store of waiting patients who have conditions that are deemed less important by the profession or society at large. ${ }^{110}$ Frankel and West noted: "Waiting lists may serve to protect individual patients and practitioners from being forced to acknowledge either the triviality or the intractability of particular conditions," a point particularly applicable to lists for an outpatient surgical consultation. ${ }^{11} 12$ But if this rationale is applied to patients on an inpatient list, there are only three possible scenarios. Firstly, a senseless game of mutual self deception might be under way, and the patient should better concentrate on non-surgical relief. Secondly, the patient may want relief and anticipate benefit from surgery, but the surgeon is less certain and so uses the queue as a temporising device. Or thirdly, there may be a mutual belief that the condition in question carries a burden truly avertible by surgery, in which case waiting merely extends avoidable suffering. Distinguishing among these possibilities demands the development and application of methods for measuring the impact of delayed treatment.

\section{. . . it is surely time to regard the experience of queueing in general as an iatrogenic state of illness amenable to standard epidemiological assessments.}

Literature based inferences about the burden of delayed surgery are possible. Bishop, for instance, reviewed the urological literature qualitatively and was "doubtful if delay in diagnosis or treatment seriously influences morbidity and mortality from urological illness." 13 However, quantitative extrapolations about the burden of delay require data from randomised trials that compare surgical procedures with medical alternatives. Coronary artery bypass grafting is one of the few procedures in which several trials of medicine versus surgery have been performed. Thus, our group was able to use these data to estimate that patients with recent unstable symptoms and left mainstem stenosis had a vital risk of about $1 \%$ per month in the queue whereas most other subgroups had risks of $0.33 \%$ per month or less. ${ }^{14}$ Such extrapolations are inevitably limited to the end points chosen by trialists and are no substitute for empirical assessments.

Follow up to assess the status of patients in a long surgical queue is arguably part of sound and compassionate practice, as well as an opportunity for epidemiological research. In fact, since waiting lists have existed in some countries for 40 years it is surely time to regard the experience of queueing in general as an iatrogenic state of illness amenable to standard epidemiological assessments. ${ }^{15}$
Study designs for such assessments can parallel the usual methods. For example, simple cross sectional studies can provide useful snapshots of distress or disability in the queue; however, sequential assessments are crucial given the variable booking patterns of surgeons and patients. As Sanderson noted over a decade ago, ${ }^{16}$ one ophthalmologist may hedge his bets by placing every patient with cataract on the surgical list and following them up; he will have a lengthy queue and many cancellations or non-attenders. Another who books only patients with deteriorating visual acuity will have a shorter queue of patients who can little afford to wait.

Postoperative assessment is crucial to determine how much improvement occurs in the outcome of interest - an after-before comparison in which the goal is to calculate how much of the suffering in the queue could have been relieved by more expeditious surgery. However, the avertible burden may be underestimated if postoperative outcomes are compromised by preoperative delays. Matters are more complex still for cancer surgery, in which long postoperative follow up would be needed to rule out decreased survival owing to tumour progression or metastasis in the queue.

The known variability in the length of queues among hospitals and regions can be seen as a set of natural experiments relating outcomes to delays. Comparisons between private and NHS care allowed Marber et al to suggest that more rapid referrals to private coronary surgery led to fewer deaths in the queue. ${ }^{17}$ The clearest answers relating delay to both preoperative burden and postoperative outcomes would come from a randomised trial of accelerated versus conventional care - a notion that may seem heartless or even unethical. But if resources are insufficient to shorten the queue for all, perhaps randomisation can make a virtue of necessity.

Outcomes from the patient's perspective One convenient way to categorise the burden of delay from the patient's perspective is with the "seven Ds" schema, modified by our group $^{18}$ from White's work ${ }^{19}$ : death, disease, dysfunction, disability, dissatisfaction, distress, and destitution.

Of these outcomes, death is rare and most commonly reported among patients awaiting heart surgery. Two Canadian studies of coronary artery bypass grafting each showed that about $1 \%$ of patients booked consecutively died in the queue 2021 whereas a Dutch group calculated that 8.3 patients died per 100 patient years of waiting time. ${ }^{22}$ Using a case-control method, the Dutch group also assessed predictors of death in the queue for coronary artery bypass grafting and identified some important factors, such as persistent smoking. ${ }^{16}$ A more useful observation may be that the death rate in the Dutch study was twice that of the Canadian studies, and the waiting times were two to three times as long. Much more study, however, is needed to identify risk factors for death in the queue for 
cardiac surgery and to determine how those factors can be modified.

As to dysfunction and disability, a survey of consultants in British Columbia in the autumn of 1989 asking them to estimate the percentage of waiting patients "experiencing significant difficulty in carrying on their work or daily duties as a result of their medical condition" showed proportions ranging from as low as $14 \%$ for gynaecology to $88 \%$ for cardiovascular services. ${ }^{23}$ However, these informal estimates by proxy, particularly from proxies with an interest in expanding resources, are a poor substitute for empirical data from patients.

Psychological distress has received limited study among patients awaiting surgery. Pieper et al assessed anxiety, depression, and impact on spousal relationships for 28 selected men waiting for coronary artery bypass grafting. ${ }^{24}$ Paradoxically, scores were worse for those who underwent faster surgery, presumably because of the implicit message that these men were more seriously ill. There was no control group and no after-before comparison to determine the relief of distress after surgery. Mulgan and Logan found no correlation between waiting time for coronary artery bypass grafting and patients' anxiety levels; more psychological distress was observed among the patients' spouses, $45 \%$ of whom thought their own health had suffered because of the delayed surgery. ${ }^{25}$ This point reminds us that, in psychosocial terms, the burden of waiting may extend beyond the patient, to his or her family and to wider social networks. Much larger samples, better study designs, and more advanced batteries of tests are needed to deepen our understanding of these issues.

\section{... waiting lists ... have become a political tool to palliate policies of implicit denial....}

Lastly, when disability and destitution are considered together, it has been claimed that $5-10 \%$ of all patients on surgical waiting lists are employed persons on sick leave caused by delayed surgery. ${ }^{26} \mathrm{~A}$ Finnish study found that 57 of 100 open heart surgery patients were actively working when first placed on a lengthy waiting list but only four were still working by the time of surgery. ${ }^{27}$ The authors developed a multivariate model showing that six months of preoperative disability, rather than waiting time itself, predicted failure to return to work after surgery. But since waiting time and length of preoperative disability are closely related, the lack of impact of waiting time in the multivariate model may represent the statistical phenomenon of "distraction by proxy." Again, the conclusion is that we need to know more about the hidden burdens and costs of delayed treatment.

\section{Conclusion}

In theory, all a queue does is put off the time that a service is delivered. But in many countries waiting lists have ceased to be an explicit mechanism of managed delay that preserves equitable access to finite public resources; they have instead become a political tool to palliate policies of implicit denial, cloaked in the apparent egalitarianism of universal coverage. ${ }^{15}$ Waiting lists for surgery and for a host of tests and treatments accordingly pose a challenge to the moral underpinnings of public health care system, a challenge that has been poorly met by the clinical research community. Beyond debates about how many are waiting and for how long, the underlying issue is the burden of delay namely, the years with impaired quality of life in queues for different procedures, the irreversible deterioration of psyche and soma, the avoidable deaths in the queue or after surgery, the personal loss of productivity, and the myriad hidden costs of queueing within the health system and society. If these burdens are rigorously measured and reported practitioners and managers can make stronger arguments for new resources in public health care systems. Without these data, existing resources and new funds alike may be misspent.

1 Pope C. Trouble in store: some thoughts on the management of waiting lists. Sociology of Health and Illness 1991; 13:193-212.

2 Freeland AP, Curley JWA. The consequences of delay in tonsil surgery. Otolaryngol Clin North Am 1987;20: 405-8.

3 Barry MJ, Mulley AG, Fowler FJ, Wennberg JE. Watching waiting vs immediate transurethral resection for symptomatic prostatism: the importance of patient symptomatic prostatism: the importanc
preferences. $F A M A 1988 ; 259: 3010-17$.

4 Brewster SF, Nicholson S, Farndon JR. The varicose vein waiting list: results of a validation exercise. Ann R Coll waiting list: results of a valid

5 Tomlinson $M$, Cullen J. A clinical audit of patients on an orthopaedic waiting list for greater than two years. NZ Med $\mathscr{f}$ 1992;105:266-8.

6 Rigge M. Guide to hospital waiting lists. 6th ed. London: College of Health, 1990.

7 Miyake J, Walker M. Waiting your turn: hospital waiting lists in Canada. Critical Issues Bulletin I. 3rd ed. Vancouver: The Fraser Institute, 1993.

8 Naylor CD. Levinton CM, Wheeler S, et al. Queueing for coronary surgery during severe supply-demand mismatch in a Canadian referral centre: a case study of implicit rationing. Soc Sci Med 1993;37:61-7.

9 Pope CJ, Roberts JA, Black NA. Dissecting a waiting list. Health Service Management Research 1991;4:112-9.

10 Harvey I. And so to bed: access to inpatient services. In: Farvey $\mathrm{I}$. And so to bed: access to inpatient services. In:
Frankel $\mathrm{S}$, West $\mathrm{R}$, eds. Rationing and rationality in the Frankel S, West $\mathrm{R}$, eds. Rationing and rationality in the
National Health Service. The persistence of waiting lists. National Health Service. The persis

11 Frankel S. The origins of waiting lists. In: Frankel S, West $\mathrm{R}$, eds. Rationing and rationality in the National Health Service. The persistence of waiting lists. London MacMillan 1993:1-40.

12 Frankel S, West R. What is to be done? In: Frankel S, West $\mathrm{R}$, eds. Rationing and rationality in the National Health Service. The persistence of waiting lists. London MacMillan 1993:115-31.

13 Bishop MC. The dangers of a long urological waiting list. $\mathrm{Br} \mathcal{F}$ Urol 1990;65:433-40.

14 Rachlis MM, Olak J, Naylor CD. The vital risk of delayed coronary surgery: lessons from the randomized trials. Iatrogenics 1991;1:103-11.

15 Naylor CD. A different view of queues in Ontario. Health Aff (Millwood) 1991;10:110-28.

16 Sanderson HF. What's in a waiting list? BMF 1982; 285:1368-9.

17 Marber $M$, MacRae C, Joy $M$. Delay to invasive investigation and revascularisation for coronary heart investigation and revascularisation for coronary heart disease in South West Thar

18 Health Services Research Group. Outcomes and the management of health care. Can Med Assoc $\mathcal{F}$ 1992; management

19 White K. Improved medical statistics and health services systems. Public Health Rep 1967;82:847-54. 
20 Naylor CD, Morgan CD, Levinton CM, et al. Waiting for coronary revascularization in Toronto: two years' experience with a regional referral office. Can Med Assoc f 1993;149:955-62.

21 Cox JL, Petrie JS, Pollak PT, Landymore RW, Johnstone DE. Is queueing for coronary bypass surgery safe? A Canadian perspective (abstr). Circulation 1993;88(suppl Canadian perspective (abstr). Circulation 1993,88 (supp

22 Suttorp MJ, Kingma JH, Vos J, et al. Determinants for early mortality in patients awaiting coronary artery bypass graft surgery: a case-control study. Eur Hear $\mathcal{7} 1992$ $13: 238-42$
23 Globerman S. A policy analysis of hospital waiting lists. foumal of Policy Analysis and Management; 10:247-62.

24 Pieper B, Lepczyk M, Caldwell M. Perceptions of the waiting period before coronary artery bypass grafting. Heart Lung 1985;14:40-4.

25 Mulgan R, Logan RL. The coronary bypass waiting list: a social evaluation. $N Z$ Med f 1990;103:371-2.

26 Nord E. Reducing sick leave costs by shortening waiting o. Reducing sick leave costs by shortening waiting periods for elective surgery. Med Dicis Making

Konttinen M, Merikallio E. Return to work after open heart surgery: impact of long waiting lists? Theor Surs $1990 ; 5: 192-5$

c

$\stackrel{2}{\underline{2}}$

$\frac{1}{\mathbb{D}}$

กิ

$\overrightarrow{\overline{\vec{T}}}$ 